\title{
Continuous Inhibition of Sonic Hedgehog Signaling Leads to Differentiation of Human-Induced Pluripotent Stem Cells into Functional Insulin-Producing $\beta$ Cells
}

\author{
Song Lee $\mathbb{D}^{1}{ }^{1}$ Jae Hyun Joo, ${ }^{2}$ Ju Yun Oh, ${ }^{2,3}$ Eun Ha Seo, ${ }^{1}$ Yang Hee Kim, ${ }^{1}$ Eunsung Jun, ${ }^{1}$ \\ In Kyong Shim, ${ }^{1}$ and Song Cheol Kim $\mathbb{D}^{1,2,3,4}$ \\ ${ }^{1}$ Asan Institute for Life Science, Asan Medical Center, University of Ulsan College of Medicine, 88 Olympic-ro 43-gil, Songpa-gu, \\ Seoul 05505, Republic of Korea \\ ${ }^{2}$ Department of Medicine, University of Ulsan College of Medicine, 88 Olympic-ro 43-gil, Songpa-gu, Seoul 05505, Republic of Korea \\ ${ }^{3}$ Asan Medical Institute of Convergence Science and Technology (AMIST), Asan Medical Center, University of Ulsan College \\ of Medicine, 88 Olympic-ro 43-gil, Songpa-gu, Seoul 05505, Republic of Korea \\ ${ }^{4}$ Division of Hepato-Biliary and Pancreatic Surgery, Department of Surgery, Asan Medical Center, University of Ulsan College \\ of Medicine, 88 Olympic-ro 43-gil, Songpa-gu, Seoul 05505, Republic of Korea
}

Correspondence should be addressed to Song Cheol Kim; drksc@amc.seoul.kr

Received 29 November 2020; Revised 22 March 2021; Accepted 29 March 2021; Published 7 April 2021

Academic Editor: Shuiqiao Yuan

Copyright $\odot 2021$ Song Lee et al. This is an open access article distributed under the Creative Commons Attribution License, which permits unrestricted use, distribution, and reproduction in any medium, provided the original work is properly cited.

\begin{abstract}
Human-induced pluripotent stem cell- (iPSC-) derived insulin-producing cells (IPCs) can be used for islet cell transplantation into type 1 diabetic patients and as patient-specific cells for the development of novel antidiabetic drugs. However, a method is needed to generate functional IPCs from iPSCs and simplify the protocol. We compared combinations of small molecules that could induce the differentiation of cells into a definitive endoderm and preferentially into islet precursor cells. When generated using an optimal combination of small molecules, IPCs secreted insulin in response to glucose stimulation. We constructed spheroid IPCs and optimized the culture and maturation conditions. Quantitative PCR revealed that the expression of definitive endoderm-specific markers differed depending on the combination of the small molecules. The small molecule, $\mathrm{N}-[(3,5-$ dimethyl-1-phenyl-1Hpyrazol-4-yl)methylene]-4-(phenylmethyl)-1-piperazinamine, induced the differentiation of cells into functional IPCs by inhibiting Sonic hedgehog signaling. Images of the 2D culture showed that IPCs formed spheroids from day 5 and continuously secreted insulin. We developed a simple differentiation method using small molecules that produced functional IPCs that responded to glucose stimulation within a relatively short period. We posit that this method along with further refinement of the differentiation process can be applied to culture IPCs that can be used in clinical trials.
\end{abstract}

\section{Introduction}

Insulin-producing cells (IPCs) derived from human embryonic stem cells (ESCs) or human-induced pluripotent stem cell (iPSCs) can be used not only for transplanting islet cells, which are destroyed by autoimmunity in patients with type 1 diabetes mellitus, but also for identifying novel targets for the development of antidiabetic drugs in vitro. Several studies have differentiated IPCs from ESCs or iPSCs [1-5] by mimicking pancreatic development, and a stepwise protocol has been established $[3,4,6-8]$. This protocol requires adding various factors to culture media at each stage of pancreatic differentiation, to induce transcription factors that are specific to each stage. Small molecules are popular inducers of differentiation, and the function of IPCs generated in this manner is robust in vivo and in vitro [9-12].

Many small molecules have been identified that can be applied in vitro and in vivo to grow stem cells [13-15], direct their differentiation $[10,11,16-18]$, and reprogram somatic cells into a more naïve state [19]. These molecules also provide useful information about the signaling and differentiation mechanisms that regulate stem cell biology. Small 
TABLE 1: Function and application of small molecules in the differentiation of cells into insulin-producing cells.

\begin{tabular}{|c|c|c|c|}
\hline Step & Name & Function & Application \\
\hline \multirow{3}{*}{1} & CHIR99021 & Inhibitor of glycogen synthase kinase 3 (GSK-3) & Induces definitive endoderm formation \\
\hline & LY294002 & Inhibitor of phosphatidylinositol 3-kinase (PI3K) & Induces definitive endoderm formation \\
\hline & Activin A & A member of the TGF- $\beta$ superfamily & Induces definitive endoderm formation \\
\hline \multirow{6}{*}{2} & FGF2 & Fibroblast growth factor (FGF) family & Promotes pancreatic endoderm \\
\hline & Dorsomorphin & Inhibitor of the BMP pathway & Promotes pancreatic endoderm \\
\hline & Retinoic acid & Major derivatives of the vitamin A group & Promotes pancreatic endoderm \\
\hline & SB431542 & Inhibitor of ALK5/TGF- $\beta$ type I receptor & Promotes pancreatic endoderm \\
\hline & FR180204 & To block extracellular-signal-regulated kinase (ERK) & Promotes pancreatic progenitor \\
\hline & SANT-1 & Smo antagonist inhibits hedgehog signaling & Promotes pancreatic progenitor \\
\hline \multirow{3}{*}{3} & Forskolin & An adenylate cyclase activator and MAP kinase inhibitor & Promotes pancreatic $\beta$ cell differentiation \\
\hline & Dexamethasone & Glucocorticoid pathway activator & Promotes pancreatic $\beta$ cell differentiation \\
\hline & Nicotinamide & Active form of vitamin B3 & Promotes the generation of NKX6.1+progenitors \\
\hline
\end{tabular}

molecules with unique biological activities enable the establishment of new biological approaches and the development of new therapies by significantly lowering the cost of production. Therefore, we leveraged the advantages of these small molecules for IPC differentiation. We screened small molecules that induce and regulate the differentiation of stem cells into pancreatic progenitor cells. These included dorsomorphin (Dor), a selective inhibitor of bone morphogenetic protein (BMP) signaling [9, 20]; SB431542, an inhibitor of transforming growth factor- $\beta$ type I receptor/ALK5 $[9,21$, 22]; N-[(3,5-dimethyl-1-phenyl-1H-pyrazol-4-yl)methylene]-4-(phenylmethyl)-1-piperazinamine (SANT-1), an inhibitor of Sonic hedgehog signaling [23-26]; FR180204 an ATP-competitive inhibitor of extracellular signal-related kinase 1 (ERK1) and ERK2 [20, 27], and retinoic acid [2830]. We developed functional IPCs that secrete insulin in response to glucose combined with these small molecules.

Although ESC- or iPSC-derived IPCs with functions similar to those of natural islet cells have been generated, they do not secrete insulin in response to glucose $[5,20,24]$. This is because differentiation and culture conditions in vitro do not accurately mimic the natural stages of human pancreatic development. Therefore, although combining differentiation-inducing factors is important, the method of producing these cells in culture must also be improved.

We developed a simple and efficient stepwise protocol for generating IPCs from iPSCs using SANT-1 and FR180204. We induced the differentiation of iPSCs into a definitive endoderm, pancreatic progenitor cells, and finally, IPCs. In addition, the functional IPCs were continuously cultured and matured to attain a spheroid morphology similar to that of natural islet cells.

\section{Materials and Methods}

2.1. Small Molecules. Several small molecular compounds that inhibit cellular signaling pathways have been applied to differentiate iPSCs into IPCs. We divided the differentiation process into three steps to mimic the process of embryonic pancreatic development, namely, the formation of a defini- tive endoderm, its differentiation into pancreatic endoderm and pancreatic progenitor cells, and the specific induction of cell differentiation into IPCs. The small molecules were processed at each step, and the results were confirmed by comparing and analyzing the effects of combining these agents (Table 1 ).

2.2. Cell Culture. The iPSCs provided by the Center for Stem Cell Research of Asan Institute (Seoul, Korea) were maintained in evitronectin-coated dishes with essential $8^{\mathrm{TM}}$ basal medium (Gibco Laboratories, Gaithersburg, MD, USA). For differentiation into a definitive endoderm, cells were dispersed with TrypLE ${ }^{\mathrm{TM}}$ expression enzyme (Thermo Fisher Scientific Inc., Waltham, MA, USA) , and then $2 \times 10^{5}$ cells $/ \mathrm{mL}$ were seeded in essential $8^{\mathrm{TM}}$ basal medium with $10 \mathrm{mM}$ Y27632 (Selleck Chemicals, Houston, TX, USA). The medium was changed $24 \mathrm{~h}$ later to Essential $8^{\mathrm{TM}}$ basal medium without Y27632. We cultured iPSCs in RPMI 1640 medium (Invitrogen, Carlsbad, CA, USA) containing 1\% B27 ${ }^{\mathrm{TM}}$ supplement (minus insulin, Invitrogen) with or without human activin A (100 ng/mL) (PeproTech, Rocky Hill, NJ), $3 \mu \mathrm{M}$ CHIR99021 (Sigma-Aldrich Corp., St. Louis, MO, USA), and $5 \mu \mathrm{M}$ LY294002 (Sigma-Aldrich Corp.) for $24 \mathrm{~h}$, followed by RPMI 1640 medium containing 1\% B27 with activin A $(100 \mathrm{ng} / \mathrm{mL})$ for $48 \mathrm{~h}$. The iPSCs were subsequently incubated in Improved MEM Zinc Option culture medium (Invitrogen) containing $1 \%$ B27 with $1 \mu \mathrm{M}$ Dor (Sigma-Aldrich Corp.), $4 \mu \mathrm{M}$ RA, $10 \mu \mathrm{M}$ SB431542 (Tocris Bioscience, Bristol, UK), with or without FGF2 (50 ng/mL, PeproTech Inc., Rocky Hill, NJ, USA), $3 \mu \mathrm{M}$ FR180204, and $0.25 \mu \mathrm{M}$ SANT-1 (both from Sigma-Aldrich Corp.) for differentiation into pancreatic progenitor cells. The cells were then cultured in differentiationinducing medium for $6 \mathrm{~d}$, and the medium was changed daily. Finally, for differentiation into IPCs, $10 \mu \mathrm{M}$ each of forskolin (For), dexamethasone (Dex), and nicotinamide (Nic) (all from Sigma-Aldrich Corp.) was added to the medium, and the cells were allowed to differentiate for $10 \mathrm{~d}$.

2.3. Teratoma Analysis. The iPSCs were harvested and dissociated into single-cell suspensions using TrypLE ${ }^{\mathrm{TM}}$ Express 


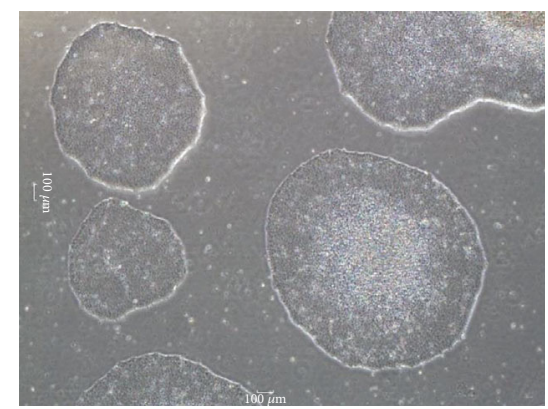

(a)
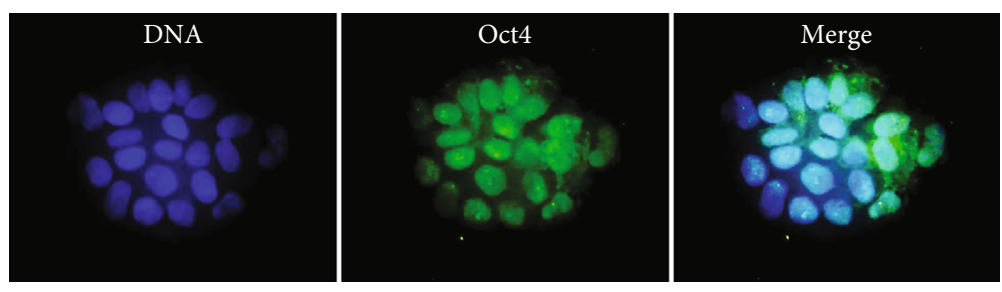

(b)
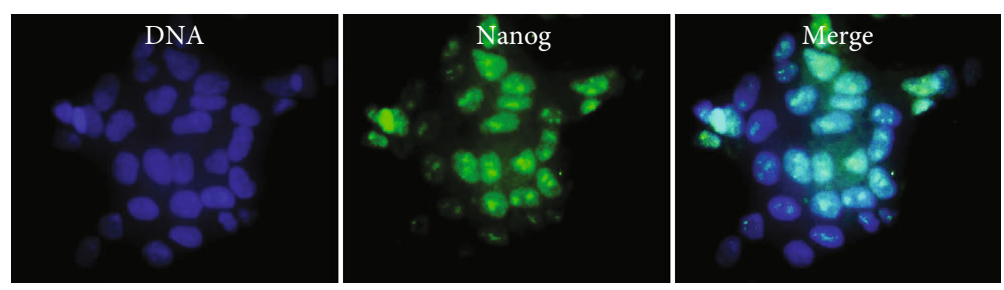

(c)
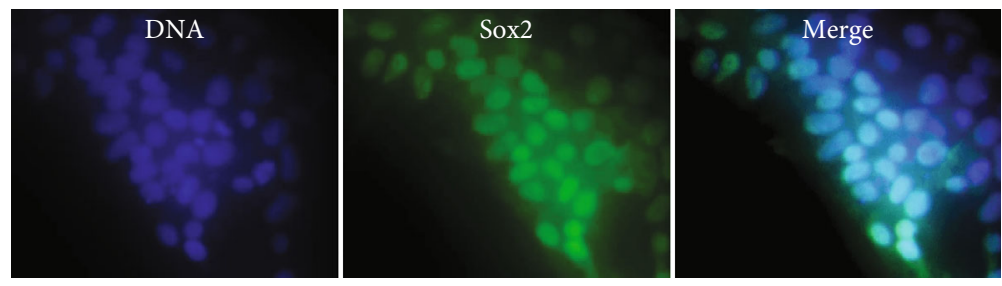

(d)
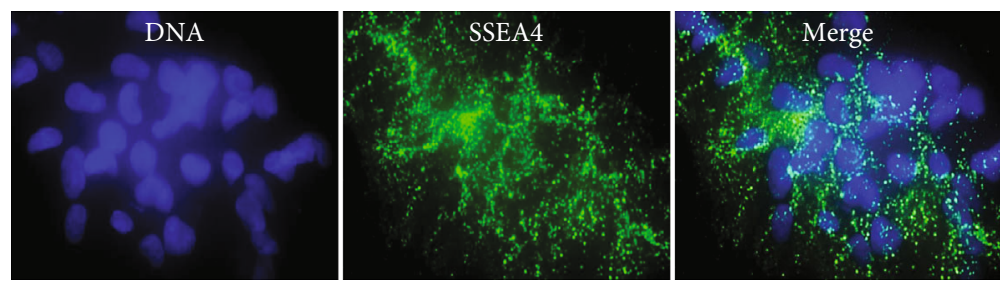

(e)

Figure 1: Continued. 


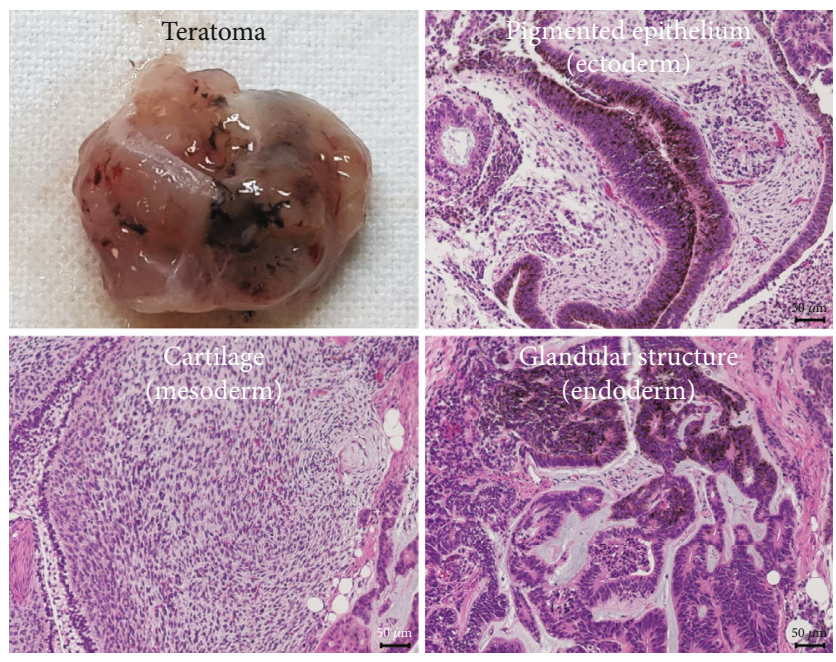

(f)

FIGURE 1: Characterization of human-induced pluripotent stem cells (iPSCs). (a) Undifferentiated iPSC colonies. Fully reprogrammed iPSC colonies are round, compact cell aggregates with sharp, distinct borders. Immunostaining of (b) Oct4, (c) Nanog, (d) Sox2, and (e) SSEA4 in undifferentiated iPSCs. (f) Teratoma derived from immunodeficient mice injected with iPSCs. Human-induced pluripotent stem cells from tissues representing embryonic germ layers: pigmented epithelium (ectoderm), cartilage (mesoderm), and glandular structure (endoderm).

(Gibco), and then $2 \times 10^{6}$ cells were subcutaneously injected dorsally into 8 -week-old mice with severe combined immunodeficiency. The mice were maintained under non-specific pathogen-free (SFP) conditions at an experimental animal facility in Asan Institute, and euthanized after the tumors reached $>1 \mathrm{~cm}^{3}$, or after an observation period of $40 \mathrm{~d}$. Tissues containing tumors were fixed with $4 \%$ paraformaldehyde (PFA), embedded in paraffin, and cut into serial $4 \mu \mathrm{m}$ sections. The sections were then stained with hematoxylin and eosin and histologically analyzed by microscopy.

2.4. Immunostaining. Cells were fixed with 4\% PFA for $30 \mathrm{~min}$ at room temperature (RT), then washed three times with phosphate-buffered saline (PBS). The cells were permeabilized with $0.1 \%$ Triton X-100 for $5 \mathrm{~min}$, then washed with PBS. Nonspecific protein binding was blocked by incubating the cells with normal horse serum $(1: 30)$ for $30 \mathrm{~min}$. Thereafter, the cells were incubated overnight at $4{ }^{\circ} \mathrm{C}$ with the following primary antibodies: rabbit anti-Oct4, diluted 1:50; mouse anti-Nanog, diluted 1:200; rabbit anti-Sox2, diluted 1:1000; mouse anti-SSEA4, diluted 1:200; mouse antiFoxA2, diluted 1:100; goat anti-CXCR4, diluted 1:300; goat anti-Pdx1 diluted 1:10000 (All from Abcam Plc., Cambridge, UK); mouse anti-insulin, diluted 1:200; and rabbit anti-glucagon, diluted 1:200 (Santa Cruz Biotechnology Inc., Dallas, TX, USA). The cells were washed with PBS, then incubated with Alexa Fluor 488- or 594-conjugated donkey or goat antibodies directed against rabbit, goat, or mouse IgG at a 1:250 dilution at RT for $1 \mathrm{~h}$. Nucleotides were stained with Hoechst 33342 (Thermo Fisher Scientific Inc.).

\subsection{Quantitative Real-Time Reverse Transcription} Polymerase Chain Reaction. Total RNA was isolated using TRIzol Reagent (Invitrogen), and then first strand cDNA was reverse-transcribed using SuperScript III First-Strand Synthesis SuperMix (Invitrogen) with RNA integrity num- bers of 9 to 10 . Levels of mRNA transcripts relative to that of 18S RNA were determined using premixed SsoAdvanced ${ }^{\mathrm{TM}}$ Universal SYBR ${ }^{\circledR}$ Green Supermix (Bio-Rad Laboratories Inc., Hercules, CA, USA) and specific primers. Samples were analyzed in duplicate, and values were averaged. The forward and reverse primer sequences were as follows $\left(5^{\prime} \rightarrow 3^{\prime}\right)$ : Sox17, CGCTTTCATGGTGTGGGCTAAGGACG and TAGTTGGGGTGGTCCTGCATGTGCTG; FoxA2, ACTG GAGCAGCTACTTAGCAGAGC and TCATGGAGTTC ATGTTGGCGTAG; CXCR4， GGTGGTCTATGTTGGC GTCT and TGGAGTGTGACAGCTTGGAG; Pdx1, GCAT CCCAGGTCTGTCTTCT and ATCCCACTGCCAGAAA GGTT; Ngn3, CTTGCTGCTCAGGAAATCCC and CTTC TGGTCGCCAAGTTCAG; Nkx6.1, CGTTGGGGATGACA GAGAGT and TGGGATCCAGAGGCTTATTG; Sox9, TACGACTACACCGACCACCA and TCAAGGTCGAG TGAGCTGTG; NeuroD, GCCGACGGAGATTAGGAGAA and TCTTGTCCTGACACTGGCAT; Insulin, ATCCTG GATCTCAGCTCCCT and CTCACAGCCCTTCAGA GAC; Glucagon, ATTGCTTGGCTGGTGAAAGG and TATAAAGTCCCTGGCGGCAA; 18S RNA, GAGCCT GCGGCTTAATTTGA and AACTAAGAACGGCCAT GCAC-3. The PCR amplification protocol comprised 45 cycles of $20 \mathrm{~s}$ at $98^{\circ} \mathrm{C}, 20 \mathrm{~s}$ at $55^{\circ} \mathrm{C}$, and $20 \mathrm{~s}$ at $72^{\circ} \mathrm{C}$. Relative levels of gene mRNA transcripts to that of $18 \mathrm{~S}$ RNA were analyzed using the $2^{-\Delta \Delta C T}$ method.

2.6. Insulin Release Assay. Differentiated cells were incubated in Krebs-Ringer bicarbonate HEPES buffer $(115 \mathrm{mM} \mathrm{NaCl}$, $24 \mathrm{mM} \quad \mathrm{NaHCO}_{3}, 5 \mathrm{mM} \mathrm{KCl}, 2.5 \mathrm{mM} \quad \mathrm{CaCl}_{2}, 1.2 \mathrm{mM}$ $\mathrm{KH}_{2} \mathrm{PO}_{4}, 1.2 \mathrm{mM} \mathrm{MgSO}$, and $25 \mathrm{mM} \mathrm{HEPES)} \mathrm{containing}$ $0.5 \% \mathrm{BSA}$ and without glucose at $37^{\circ} \mathrm{C}$ for $2 \mathrm{~h}$. The cells were then sequentially incubated with $2.8,20$, and $30 \mathrm{mM}$ glucose and $30 \mathrm{mM} \mathrm{KCl-Krebs}$ buffer for $1 \mathrm{~h}$. Insulin secreted by samples in Krebs buffer and in differentiation-induced media 


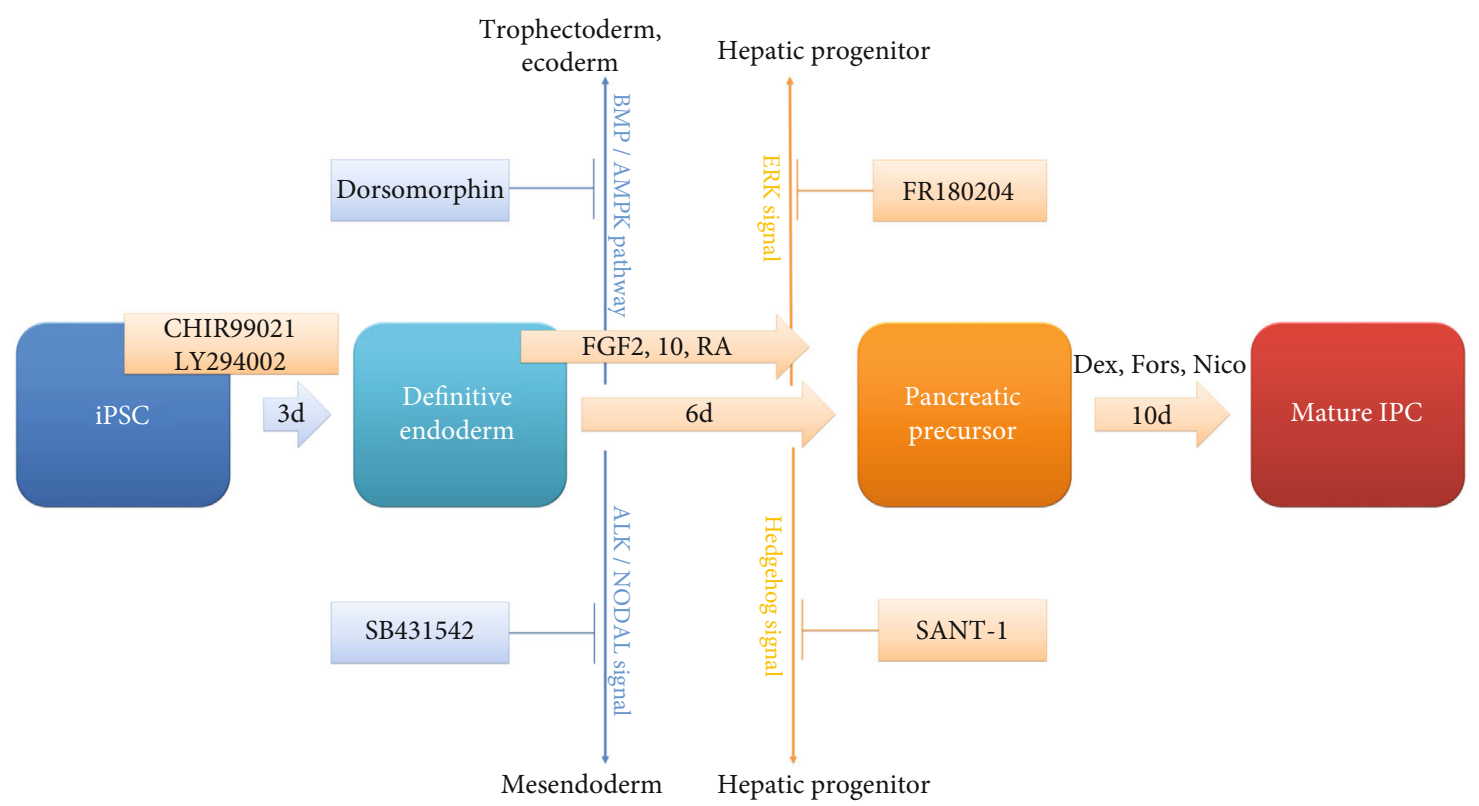

(a)

\begin{tabular}{cccc}
\hline & 1 & 2 & 3 \\
\hline Activin A & + & + & + \\
LY294002 & & & + \\
CHIR99021 & & + & + \\
\hline
\end{tabular}

(b)
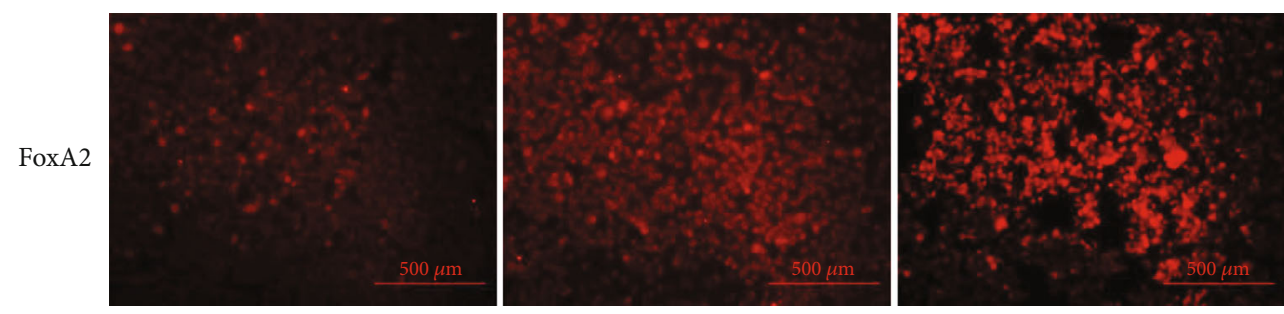

(c)
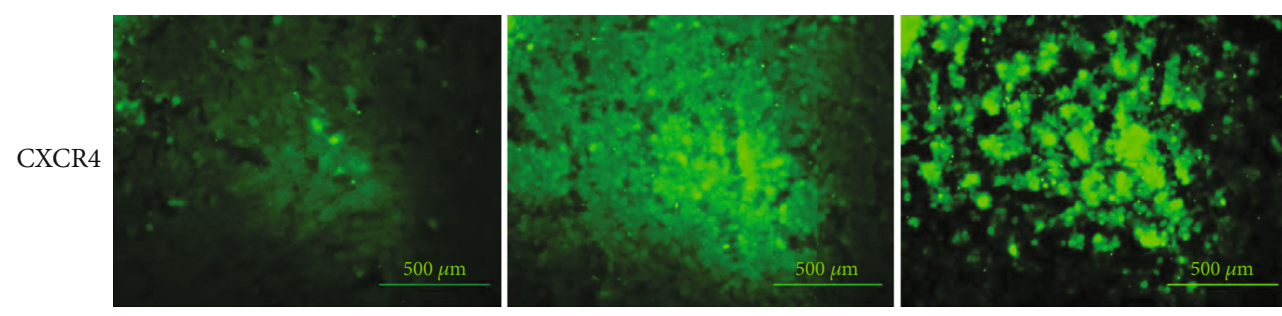

(d)

Figure 2: Continued. 


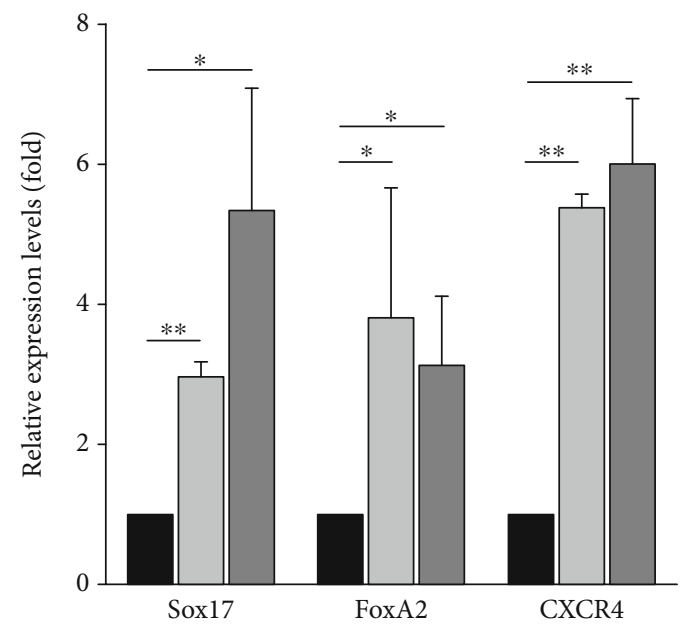

(e)

Figure 2: Comparison of small molecule combinations to induce cell differentiation into a definitive endoderm. (a) Mechanism of action of small molecules involved in IPC generation. (b) Cells cultured with activin A, LY294002, or CHIR99021 to induce differentiation into a definitive endoderm. (c) Immunostaining to detect FoxA2 in cells incubated with activin A, LY294002, and CHIR99021. (d) Abundant CXCR4 expression in cells incubated with activin A and CHIR99021, activin A, LY294002, and CHIR99021. (e) Quantitative PCR findings show the most abundant expression of Sox17 and CXCR4 mRNA, but relatively lower expression of FoxA2 mRNA in cells incubated with activin A, LY294002, and CHIR99021, than in those incubated with activin A and CHIR99021. Bars: means \pm standard deviation $(n=3) .{ }^{*} P<0.05,{ }^{* *} P<0.005$.

was measured using insulin ELISA kits (ALPCO, Salem, NH, USA).

2.7. Flow Cytometry. Differentiated cells were dissociated into single cells using Accutase, fixed with 4\% PFA, and permeabilized with Perm buffer III (BD Biosciences, San Jose, CA, USA). The cells were then incubated with normal horse serum for $10 \mathrm{~min}$, followed by mouse anti-insulin, rabbit anti-glucagon, and rabbit anti-Ngn3 antibody for $30 \mathrm{~min}$ at RT. The cells were stained with Alexa Fluor 488-conjugated donkey antibodies directed against mouse or rabbit IgG for $30 \mathrm{~min}$ at RT, and then fluorescence emission was measured by flow cytometry using a FACSAria II (Becton Dickinson).

2.8. Statistical Analyses. Standard deviation was determined using two-tailed unpaired Student's $t$-tests. Multiple comparisons were assessed, and significance was calculated using two-way ANOVA including $P$ values. All data were statistically analyzed using Prism version 8 (GraphPad Software Inc., San Diego, CA, USA). Values with $P<0.05$ were considered statistically significant.

\section{Results}

3.1. Characterization of iPSCs. We cultured iPSCs in vitronectin-coated culture dishes without feeder cells. We found that colonies of iPSCs could be maintained stably in vitro for up to 2 weeks (Figure 1(a)). Specific nuclear markers of iPSCs, namely, the homeodomain transcription factor of the POU family, Oct4 (Figure 1(b)), Nanog (Figure 1(c)), and Sox2 (Figure 1(d)), were identified by the immunostaining of undifferentiated cells. We also detected SSEA4, a representative cell surface marker of iPSCs (Figure 1(e)). We examined the pluripotency of the iPSCs using a teratoma analysis. The iPSCs that were transplanted into the mice grew into a solid mass of tissue for $40 \mathrm{~d}$, and then clusters of various tissues appeared on the tumor surface (Figure 1(f)). Sections of the solid masses histologically varied, and representative endoderm, ectoderm, and mesoderm tissues were identified. These characteristics confirmed that the iPSCs were pluripotent and had the potential to differentiate into IPCs.

3.2. Induction of iPSC Differentiation into a Definitive Endoderm Using Small Molecules. We investigated small molecules that could differentiate iPSCs into a definitive endoderm (Figure 2(a)). We compared the differentiation efficiency of CHIR99021 and LY294002 based on activin A concentrations (Figure 2(b)) on day 1 of a total induction period of $3 \mathrm{~d}$. Immunostaining revealed that cells expressed more abundant FoxA2 (Figure 2(c)), and more cells expressed CXCR4 when incubated with CHIR99021 and LY294002 together than separately (Figure 2(d)). The findings of qPCR revealed slightly less FoxA2 expression in cells incubated with both compounds than with CHIR99021 alone. More Sox17 and CXCR4 were expressed by cells incubated with both compounds (Figure 2(e)). These findings showed that CHIR99021 and LY294002 together induced the differentiation of iPSCs into a definitive endoderm more effectively than the use of either alone.

3.3. Induction of Differentiation of iPSCs into IPCs Using Combinations of Small Molecules. Although the iPSCs differentiated into a definitive endoderm, they retained the internal ability to differentiate into mesodermal and ectodermal cells. Therefore, we used small molecules to inhibit all signaling by cell differentiation pathways, except that of pancreatic progenitor cells (Figure 2(a)). We compared the effects of 


\begin{tabular}{|c|c|c|c|c|c|c|}
\hline STEP2 & $\# 1$ & & $\# 3$ & $\# 4$ & & $\# 6$ \\
\hline Dor, RA, SB431542 & + & + & + & + & + & + \\
\hline FGF2 & & + & & & + & + \\
\hline FR180204 & & & + & & + & + \\
\hline SANT-1 & & & & + & & + \\
\hline
\end{tabular}
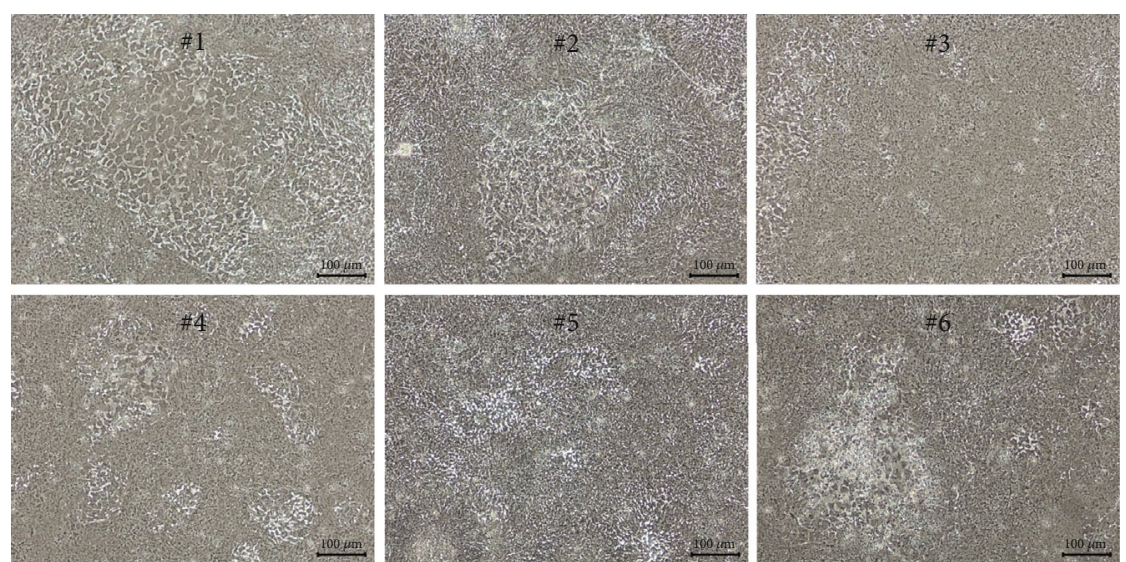

(a)
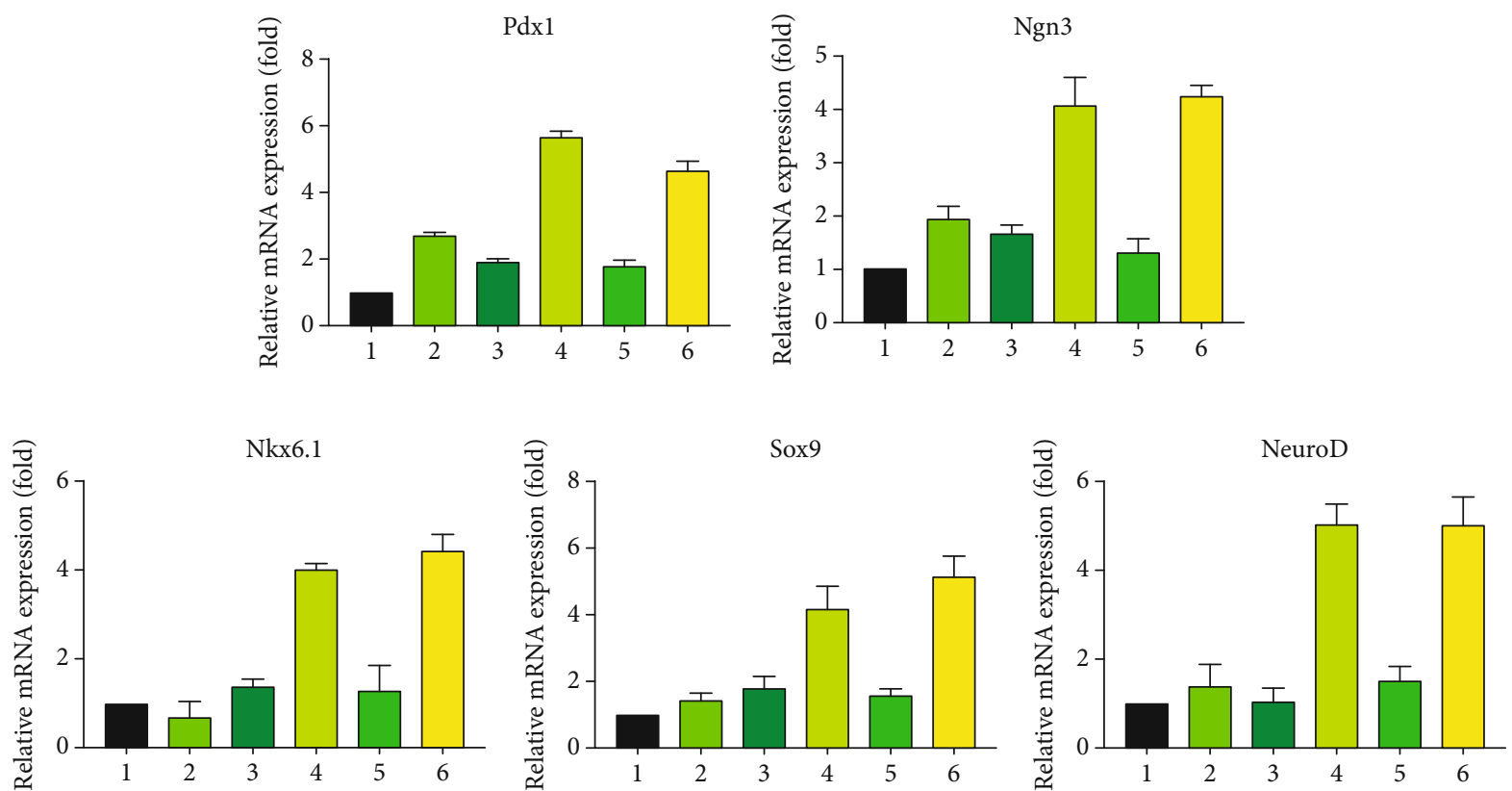

(b)

FIgURE 3: Combinations of small molecules to differentiate cells into pancreatic progenitor cells. (a) Combinations of small molecules applied in three stages to induce differentiation into islet precursor cells. Cell morphology is homogeneous in groups 4 and 6, in which SANT-1 was added to basic differentiation culture medium during step 3 of differentiation. (b) The expression of major transcription factors in pancreatic progenitor cells under all conditions compared using qPCR. The expression of major transcription factors, Pdx1, Ngn3, Nkx6.1, Sox9, and NeuroD in other groups is slightly higher than that in group 1, which was incubated with only the basic differentiation factor. Expression is the most abundant in cells incubated with SANT-1 $(n=3)$. 


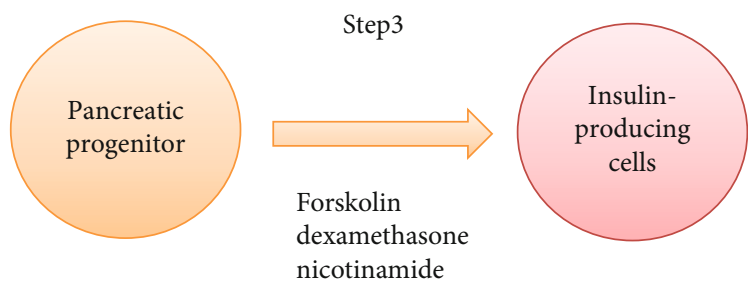

(a)
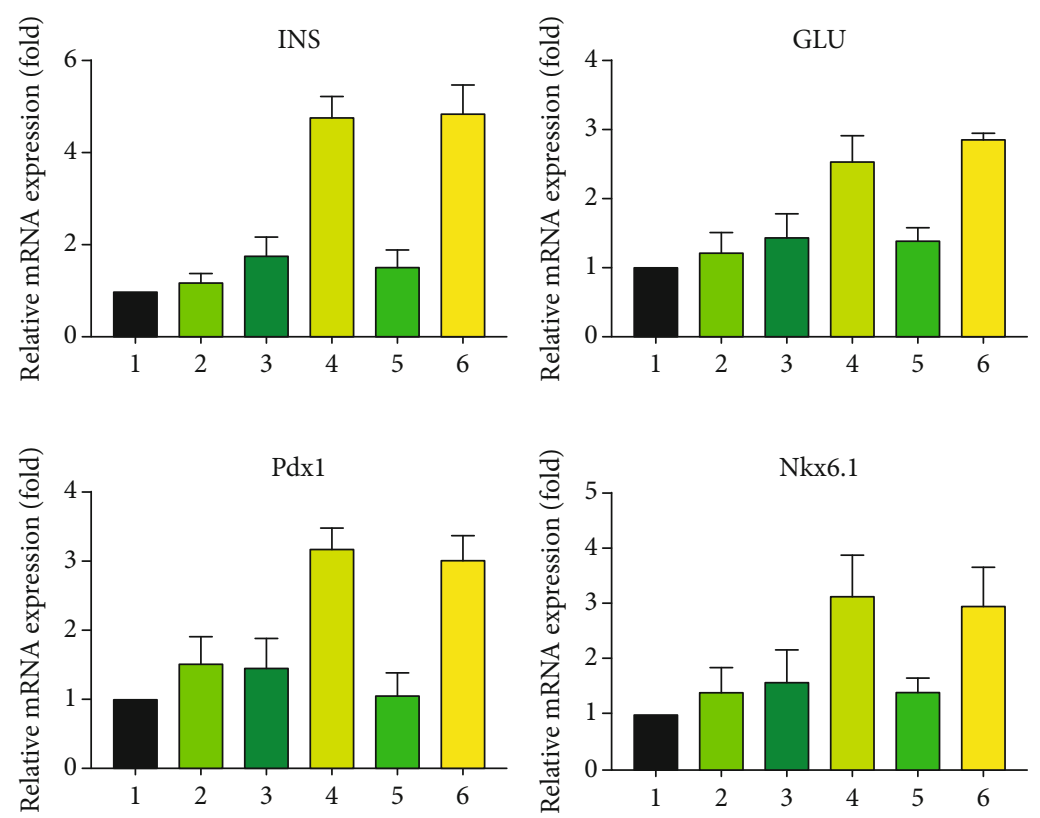

(b)
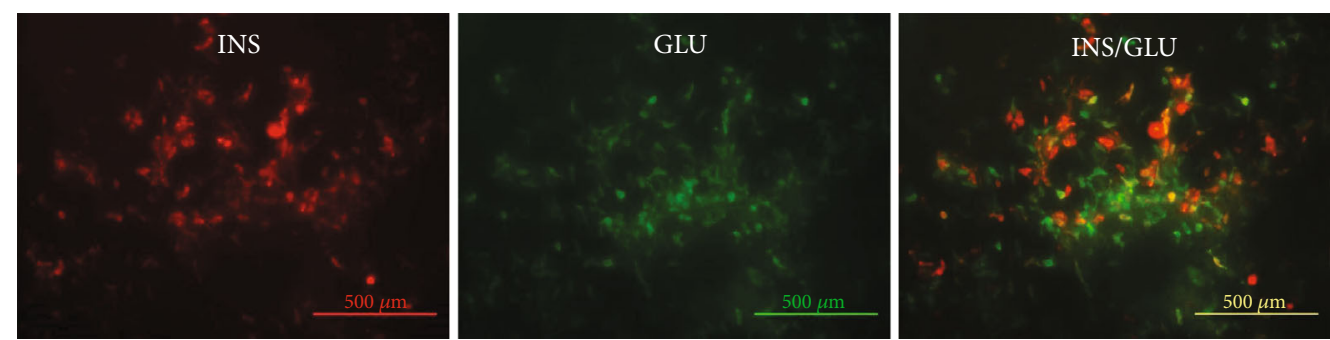

(c)
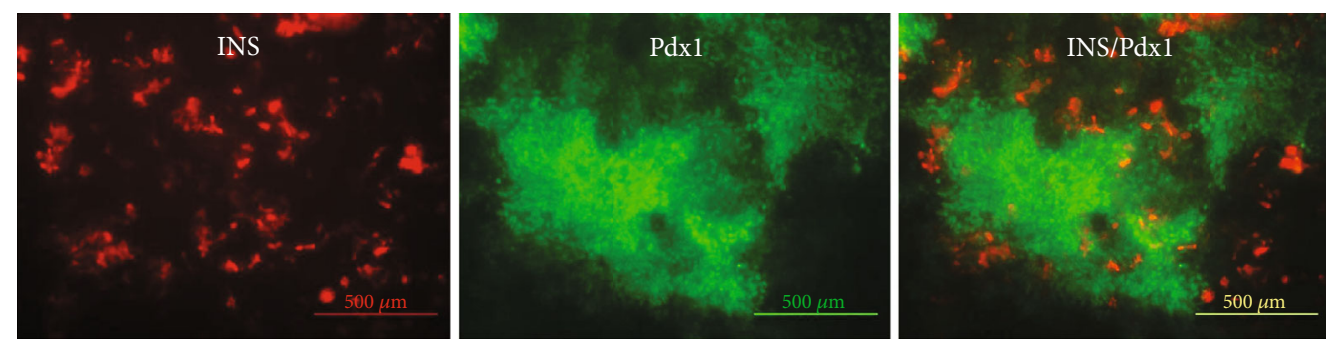

(d)

Figure 4: Continued. 

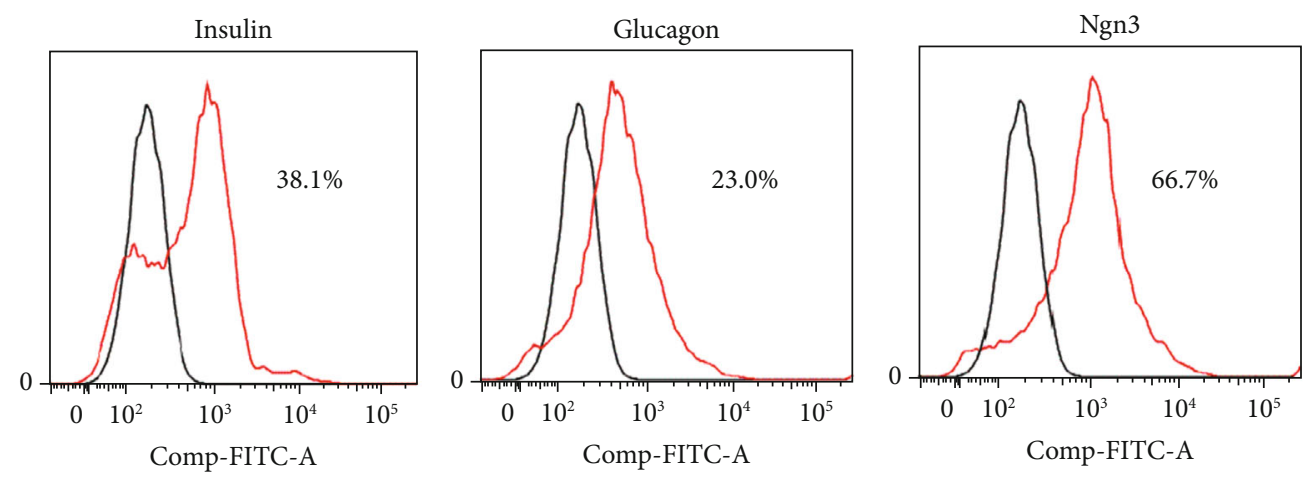

(e)

Figure 4: Differentiation of pancreatic progenitor cells into IPCs. (a) Final stage of differentiation using forskolin, dexamethasone, and nicotinamide to induce differentiation into IPCs. (b) The insulin and glucagon expression in induced cells assessed using qPCR after $10 \mathrm{~d}$ is the highest in cells incubated with SANT-1. The expression profiles of Pdx1 and Nkx6.1 were similar $(n=3)$. (c) Immunostaining of cells expressing insulin or glucagon on day 10 of differentiation step 3. (d) Insulin or Pdx1 expression on day 10 of differentiation step 3. (e) Distribution of cells expressing insulin, glucagon, and Ngn3 in differentiated cells analyzed by FACS.

small molecules that can inhibit the differentiation of cells into hepatic progenitor cells. We incubated cells in differentiation-inducing media containing Dor and SB431542 that inhibit the differentiation into ectodermal and mesodermal cells, respectively, and compared cells incubated with fibroblast growth factor 2 (FGF2), the ERK signaling inhibitor FR180204, and the hedgehog signaling inhibitor SANT-1 to cause the differentiation of cells into mature pancreatic progenitor cells. The morphology of 6-day cultured cells differed according to the conditions under which differentiation was induced. In general, all conditions induced vigorous cell growth, resulting in high cell density. However, the morphology and growth rates of the cells that did not significantly differ (Figure 3(a)). Therefore, we analyzed the expression of the transcription factor characteristic of the pancreatic progenitor cells, Pdx1, Ngn3, Nkx6.1, Sox9, and NeuroD, under all conditions. The overall expression of the transcription factors was higher than that of the basic differentiation factors in group 1 . However, the expression of each transcription factor was significantly increased in groups 4 and 6 incubated with SANT-1 compared with each transcription factor in the other groups (Figure 3(b)). These results showed that inhibiting hedgehog signaling by a specific pathway resulted in a more effective differentiation into pancreatic progenitor cells.

After differentiation into pancreatic progenitor cells induced under step 2 conditions, we similarly induced differentiation into IPCs over 8 days in culture medium containing Dex, Nic, and For (Figure 4(a)). We then used qPCR to analyze the gene expression of insulin and glucagon, which are representative hormones of mature pancreatic islet cells and the transcription factors, Pdx1, and Nkx6.1. The mean expression of each marker in all groups tended to increase compared with group 1 but did not reach statistical significance. However, the gene expression was markedly increased in groups 4 and 6 incubated with SANT-1 compared with group 1 , thus confirming the statistical significance of all groups (Figure 4(b)). Group 6 that had relatively more complete differentiation than the other groups was analyzed by immunostaining and flow cytometry. Cells that expressed insulin and glucagon were scattered among the cells in group 6. In addition, differentiation occurred in small groups rather than in large clusters (Figure 4(c)). Cells expressing Pdx1 were identified in most groups, but rarely among cells expressing insulin (Figure 4(d)). The flow cytometry findings indicated that approximately $38 \%$ of all differentiated cells expressed insulin, and 23\% expressed glucagon. The most important transcription factor of pancreatic islet cells, Ngn3, was expressed in approximately $66 \%$ of all differentiated cells (Figure 4(e)). These results indicated that a few cells could directly differentiate into islet cells even in the presence of a large number of islet progenitor cells expressing Pdx1 and Ngn3. Thus, differentiation conditions could be improved to increase differentiation efficiency.

3.4. Ability of Differentiated IPCs to Secrete Insulin. We quantified the differentiation of IPCs based on combinations of inducing factors and determined changes in the glucoseregulated quality of functional IPCs. Concentrations of insulin spontaneously secreted in culture medium were analyzed on day 5 of differentiation into mature IPCs. All groups secreted insulin, but the amount did not significantly differ among the groups (Figure 5(a)). Insulin concentrations were approximately 15 -fold higher on day 8 than on day 5 in all groups. In particular, SANT-1-treated groups 4 and 6 showed higher insulin concentrations than the other groups, and the increase in concentration did not significantly differ among the other groups (Figure 5(b)). Forskolin is an adenylate cyclase activator that is involved in the vitality and growth of cells during IPC differentiation, but it also causes mature pancreatic cells to release more insulin. Therefore, we incubated the cells for another $4 \mathrm{~d}$ after removing For and then measured insulin concentrations in the media. The insulin concentrations were decreased by $>2$-fold and slightly decreased in the cells incubated without and with SANT-1, respectively (Figure 5(c)).

We also determined whether glucose could stimulate differentiated IPCs to secrete insulin. Group 1 without SANT 


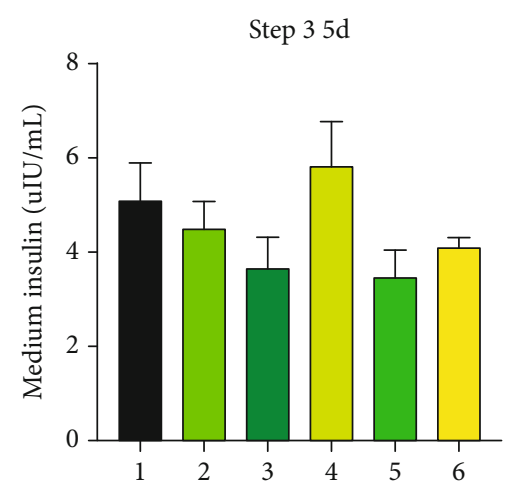

(a)

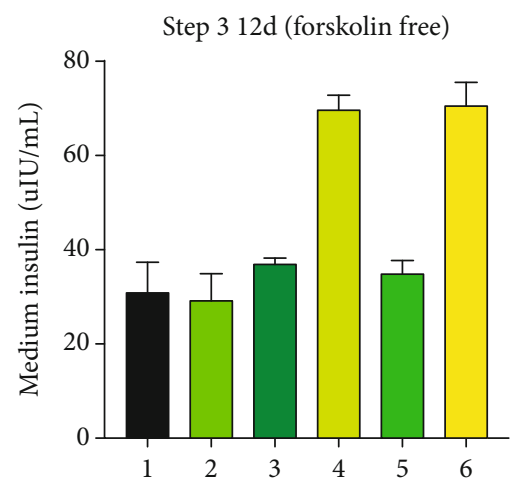

(c)

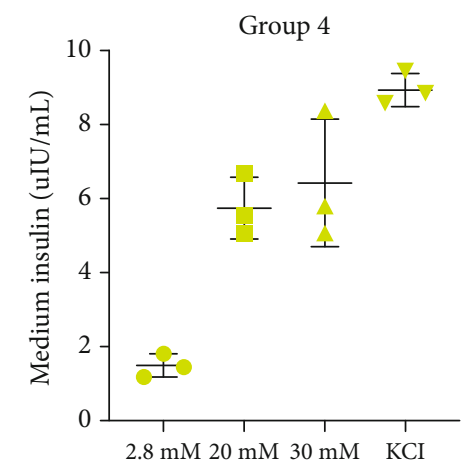

(e)

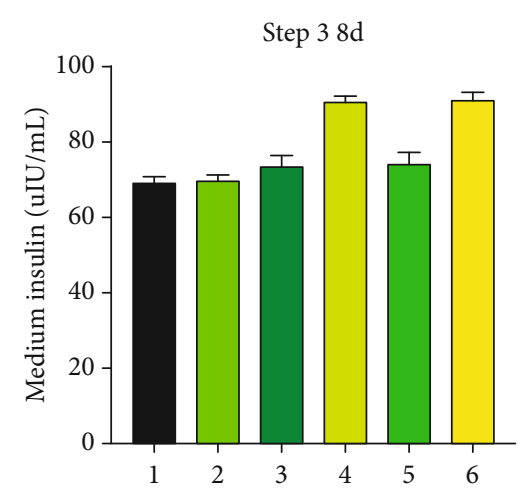

(b)

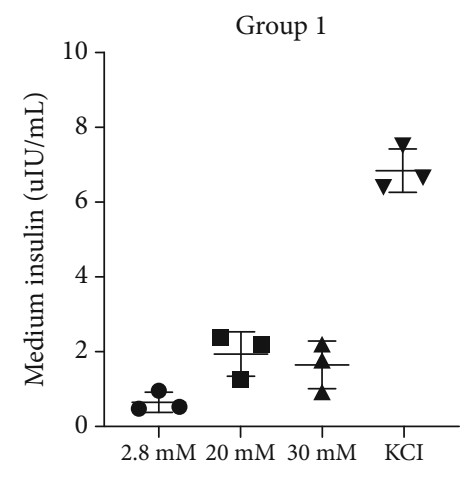

(d)

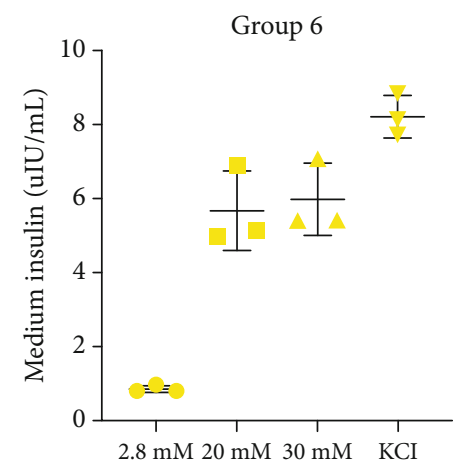

(f)

FIGURE 5: Functional abilities of differentiated IPCs. (a) Insulin detected in culture media of all groups on day 5 of differentiation step 3. Insulin levels are higher in group 4 incubated with SANT-1 than in other groups $(n=3)$. (b) Insulin secretion is significantly increased in all groups on day 8 of step 3, especially in groups 4 and 6, where values exceeded the measurement range $(n=3)$. (c) In general, insulin concentrations in culture medium without forskolin are low, except in groups 4 and $6(n=3)$. (d) The insulin expression is not significantly affected by glucose concentration in cells incubated with only the basic differentiation factor at differentiation step 2. (e) Insulin secretion is increased in response to 20 and $30 \mathrm{mM}$ glucose in group 4, which was incubated with SANT-1. (f) differentiated cells in group 4 respond to high glucose concentrations by increasing insulin secretion, like group 6.

showed increased concentration of insulin in the medium when KCL was added during differentiation, but no significant secretion based on glucose concentration was observed (Figure 5(d)). However, the group with SANT showed an increase in insulin secretion in response to a high concentration of glucose (Figures 5(e) and 5(f)). Overall, high levels of natural insulin and the ability to control insulin secretion using glucose were evident only in the group incubated with SANT-1 that inhibited hedgehog signaling mechanisms. These results suggested that inhibiting hedgehog signaling plays a major role in the differentiation of iPSCs into mature pancreatic islet cells.

3.5. IPC Culture to Create Cells Similar to Islet Cells. We differentiated IPCs using small molecules in 2D adherent cultures and attempted to cultivate spheroid clusters of IPCs similar to natural islet cells. After $10 \mathrm{~d}$ of differentiation step 3 , the cells were separated, and the cell density was high. Small cell aggregates formed on day 1 , and smaller spheroid clusters of a uniform size formed on day 5 (Figure 6(a)). 


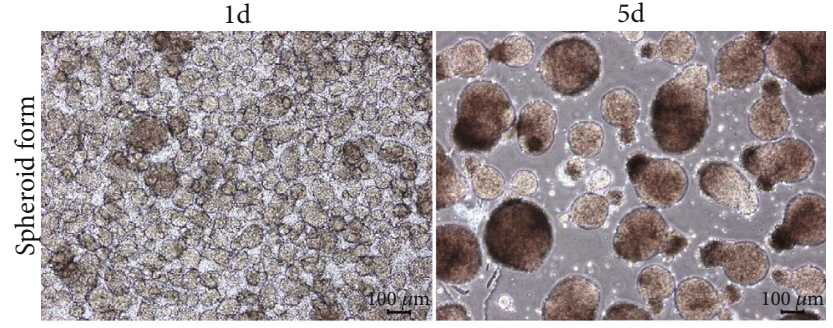

(a)

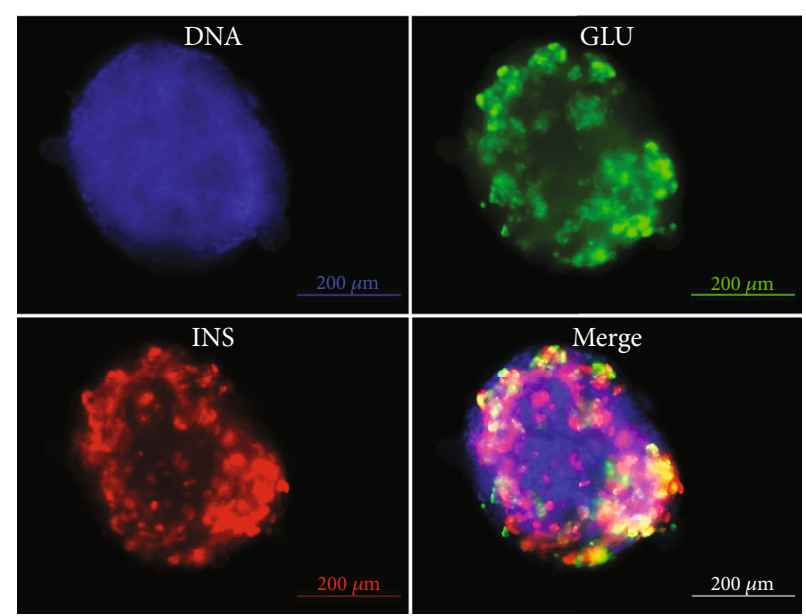

(b)

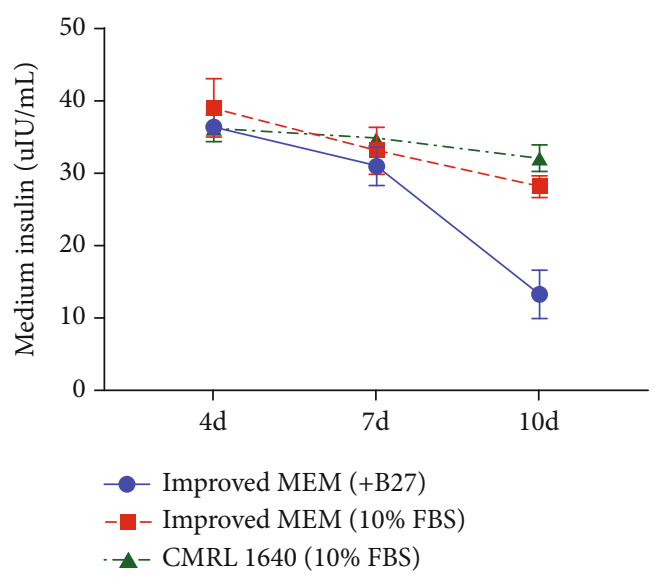

(c)

FIGURE 6: Spheroid formation and sustained maintenance of IPCs. (a) Many small clusters of IPCs form after day 1 of IPC dissociation, and numerous spheroid IPCs are generated after $5 \mathrm{~d}$. (b) Many cells express insulin or glucagon in spheroid IPCs. (c) Levels of insulin are decreased in differentiated IPCs cultured with improved MEM $(1 \times$ B27) that was used for differentiation after continuous culture for $10 \mathrm{~d}$. Cells stably secrete insulin in culture medium containing 10\% FBS.

The spheroid IPC clusters were coordinated, coherent, and expressed insulin and glucagon (Figure 6(b)). We confirmed that the spheroid morphology and basic insulin secretion ability of the IPCs could be maintained in long-term culture in vitro before transplantation in vivo.

Spheroid IPCs were maintained for a considerable period under any culture conditions. However, their ability to secrete insulin gradually decreased when incubated in a differentiation induction medium without FBS.

Basal c-peptide secretion was low but significantly decreased on day 11 when For was removed from the differentiation induction medium. Similarly, c-peptide secretion by islet cells cultured in CMRL 1066 medium was lower without, than with For, but remained stable for $7 \mathrm{~d}$ (Figure 6(c)). We suggest that the optimal conditions for culturing spheroid IPCs comprise the use of CMRL 1066 medium for $7 \mathrm{~d}$, as maintaining stable cultured normal islet cells in vitro beyond $7 \mathrm{~d}$ is difficult.

\section{Discussion}

The same method has been applied to differentiate ESCs and iPSCs in most studies of insulin-producing cells. This is because even though they are induced to differentiate by RNA-based viruses, iPSCs have the same differentiation ability as ESCs. However, iPSCs can avoid the ethical problems involved in collecting ESCs and are easily produced from adult cells. However, ESCs and iPSCs that remain undifferen- tiated after the differentiation process pose a risk of tumor formation if transplanted. This problem can be resolved using adult MSCs, but they have limited differentiation ability to differentiate into target cells. Therefore, methods of removing undifferentiated cells to prevent posttransplant tumor formation and of blocking transplanted cell growth by encapsulation are under investigation. Therefore, many other studies aim to safely transplant iPSCs in vivo.

We simply differentiated iPSCs into IPCs using small molecules to inhibit all differentiation pathways except those of IPCs. That is, we combined small molecules to ensure the natural differentiation of iPSCs towards IPCs.

We combined each of the GSK $3 \beta$-specific inhibitor CHIR99021 [20] and the phosphoinositide 3-kinase inhibitor LY294002 with activin A to induce the differentiation of iPSCs into a definitive endoderm. Slightly more FoxA2 was expressed in the group induced with CHIR99021 and activin A. However, the results of the expression of other specific markers showed that adding LY294002 would be more effective. Pancreatic progenitor cells were induced by incubating the definitive endoderm with the FGF family members, RA and Dor, as described. Therefore, we investigated whether IPC differentiation was more effective after incubation with FR180204, an ATP-competitive inhibitor of ERK1 and ERK2 [20, 27] and SANT-1 [23, 24], which inhibits differentiation into hepatocyte precursor cells [23-26]. The findings showed that SANT-1 and FR180204 increased the induction of differentiation of iPSCs into IPCs, increased insulin levels 
in culture medium, and produced functional IPCs that responded to glucose.

Many studies have investigated the generation of insulinproducing cells from stem cells. However, insulin secretion, mitochondrial metabolism, and specific gene expression of adult islet cells remain insufficient in insulin-producing cells derived from stem cells. This problem has been overcome by differentiating cells with better insulin-producing ability using PCL/PVA nanofibrous scaffolds and collagen-coated, electrospun polyethersulfone nanofibers [31, 32]. More diverse combinations of differentiation-inducing factors and signaling inhibitors have also been applied [4, 33]. Therefore, the production of mature insulin-producing cells should be further investigated from a complex perspective that considers the environment and cell signal transduction, rather than focusing on a single differentiation inducing factor. Here, we described a simple and efficient differentiation method and an important mechanism.

\section{Conclusions}

We rendered IPCs more similar to natural islet cells by culturing them to acquire a spheroid morphology because the 2D culture resulted in IPCs that did not secrete insulin in response to glucose stimulation. We applied combinations of small molecules to $2 \mathrm{D}$ cultures to induce the differentiation of iPSCs into functional IPCs that respond to glucose; however, further maturation and growth allowed the IPCs to form spheroids that were easy to transplant and could survive posttransplantation.

We suggest that inducing the differentiation of iPSCs into IPCs using this method would be suitable for human transplantation. The iPSCs were maintained and differentiated on xeno-free matrix vitronectin that supported the growth and differentiation of human iPSCs under serum-free feeder-free conditions. In addition, we induced differentiation using small molecules, which are stable, safer than protein growth factors, and economical enough for mass production.

This study differentiated iPSCs into insulin-producing cells using a new method. However, these cells did not have the same maturity as adult islet cells, and differentiation rates were low. The amount of insulin secreted by adult islet cells according to the glucose concentration is most important. The maturation stages in the differentiation process will require further detailed investigation before cells with the same ability to produce insulin as adult islet cells can be derived from stem cells. Therefore, we plan to investigate embryonic pancreas development to identify key important points involved in maturation that would be suitable for application in clinical trials.

\section{Abbreviations}

Dex: Dexamethasone

Dor: Dorsomorphin

ESCs: Human embryonic stem cells

For: Forskolin

GSIS: Glucose-stimulated insulin secretion
IPCs: Insulin-producing cells

iPSCs: Human-induced pluripotent stem cells

Nic: Nicotinamide PFA, paraformaldehyde.

\section{Data Availability}

The data used to support the findings of this study are included within the article.

\section{Ethical Approval}

Human iPSCs were obtained from Han Choe (Center for Stem Cell Research of Asan Institute) under the approval of the Institutional Review Board of Asan Medical Centre (Seoul, South Korea). The Ethics Committee of the medical faculty of Asan Medical Center approved the study, which proceeded according to the principles of the Declaration of Helsinki (2013).

\section{Conflicts of Interest}

The authors declare that they have no conflicting interests.

\section{Authors' Contributions}

SL, JHJ, JYO, EHS, and SCK conceptualized and designed the study, performed the data analysis and interpretation, and drafted and approved the article. EJ and IKS conducted the study and approved the article. Song Lee, Jae Hyun Joo, and Ju Yun Oh contributed equally to this research.

\section{Acknowledgments}

This manuscript was published in Research Square as a preprint version during the journal submission review process. This project was funded using the grants provided by the NRF-2017R1F1A1071045, NRF-2017M3A9C6032060, and NRF-2015K1A4A3046807 project of National Research Foundation (NRF) of Korea. This work was supported by the Student Research Grant (year) of University of Ulsan, College of Medicine, Seoul, Korea.

\section{References}

[1] J. V. Schiesser, S. J. Micallef, S. Hawes, A. G. Elefanty, and E. G. Stanley, "Derivation of insulin-producing Beta-cells from human pluripotent stem cells," The Review of Diabetic Studies, vol. 11, no. 1, pp. 6-18, 2014.

[2] S. G. Yabe, S. Fukuda, F. Takeda, K. Nashiro, M. Shimoda, and H. Okochi, "Efficient generation of functional pancreatic $\beta$ cells from human induced pluripotent stem cells," Journal of Diabetes, vol. 9, no. 2, pp. 168-179, 2017.

[3] J. Jiang, M. Au, K. Lu et al., "Generation of insulin-producing islet-like clusters from human embryonic stem cells," Stem Cells, vol. 25, no. 8, pp. 1940-1953, 2007.

[4] D. Zhang, W. Jiang, M. Liu et al., "Highly efficient differentiation of human ES cells and iPS cells into mature pancreatic insulin-producing cells," Cell Research, vol. 19, no. 4, pp. 429-438, 2009. 
[5] W. Jiang, Y. Shi, D. Zhao et al., "In vitro derivation of functional insulin-producing cells from human embryonic stem cells," Cell Research, vol. 17, no. 4, pp. 333-344, 2007.

[6] K. A. D'Amour, A. G. Bang, S. Eliazer et al., "Production of pancreatic hormone-expressing endocrine cells from human embryonic stem cells," Nature Biotechnology, vol. 24, no. 11, pp. 1392-1401, 2006.

[7] E. Kroon, L. A. Martinson, K. Kadoya et al., "Pancreatic endoderm derived from human embryonic stem cells generates glucose-responsive insulin-secreting cells in vivo," Nature Biotechnology, vol. 26, no. 4, pp. 443-452, 2008.

[8] H. Segev, B. Fishman, A. Ziskind, M. Shulman, and J. Itskovitz-Eldor, "Differentiation of human embryonic stem cells into insulin-producing clusters," Stem Cells, vol. 22, no. 3, pp. 265-274, 2004.

[9] Y. Kunisada, N. Tsubooka-Yamazoe, M. Shoji, and M. Hosoya, "Small molecules induce efficient differentiation into insulinproducing cells from human induced pluripotent stem cells," Stem Cell Research, vol. 8, no. 2, pp. 274-284, 2012.

[10] S. Chen, M. Borowiak, J. L. Fox et al., "A small molecule that directs differentiation of human ESCs into the pancreatic lineage," Nature Chemical Biology, vol. 5, no. 4, pp. 258-265, 2009.

[11] M. Borowiak, R. Maehr, S. Chen et al., "Small molecules efficiently direct endodermal differentiation of mouse and human embryonic stem cells," Cell Stem Cell, vol. 4, no. 4, pp. 348358, 2009.

[12] M. P. Walczak, A. M. Drozd, E. Stoczynska-Fidelus, P. Rieske, and D. P. Grzela, "Directed differentiation of human iPSC into insulin producing cells is improved by induced expression of PDX1 and NKX6.1 factors in IPC progenitors," Journal of Translational Medicine, vol. 14, no. 1, p. 341, 2016.

[13] I. Fares, L. Rivest-Khan, S. Cohen, and G. Sauvageau, "Small molecule regulation of normal and leukemic stem cells," Current Opinion in Hematology, vol. 22, no. 4, pp. 309-316, 2015.

[14] Y. Zhang, W. Li, T. Laurent, and S. Ding, "Small molecules, big roles - the chemical manipulation of stem cell fate and somatic cell reprogramming," Journal of Cell Science, vol. 125, no. 23, pp. 5609-5620, 2012.

[15] J. Shan, R. E. Schwartz, N. T. Ross et al., "Identification of small molecules for human hepatocyte expansion and iPS differentiation," Nature Chemical Biology, vol. 9, no. 8, pp. 514-520, 2013.

[16] F. Tasnim, D. Phan, Y. C. Toh, and H. Yu, "Cost-effective differentiation of hepatocyte-like cells from human pluripotent stem cells using small molecules," Biomaterials, vol. 70, pp. 115-125, 2015.

[17] F. Osakada, Z. B. Jin, Y. Hirami et al., "In vitro differentiation of retinal cells from human pluripotent stem cells by smallmolecule induction," Journal of Cell Science, vol. 122, no. 17, pp. 3169-3179, 2009.

[18] J. Liu, Y. Liu, H. Wang et al., "Direct differentiation of hepatic stem-like WB cells into insulin-producing cells using small molecules," Scientific Reports, vol. 3, no. 1, p. ???, 2013.

[19] D. Huangfu, K. Osafune, R. Maehr et al., "Induction of pluripotent stem cells from primary human fibroblasts with only Oct4 and Sox2," Nature Biotechnology, vol. 26, no. 11, pp. 1269-1275, 2008.

[20] H. Takeuchi, N. Nakatsuji, and H. Suemori, "Endodermal differentiation of human pluripotent stem cells to insulinproducing cells in 3Dculture," Scientific Reports, vol. 27, no. 4, p. 4488, 2014.
[21] S. Dhawan, E. Dirice, R. N. Kulkarni, and A. Bhushan, "Inhibition of TGF- $\beta$ signaling promotes human pancreatic $\beta$-cell replication," Diabetes, vol. 65, no. 5, pp. 1208-1218, 2016.

[22] J. du, Y. Wu, Z. Ai, X. Shi, L. Chen, and Z. Guo, "Mechanism of SB431542 in inhibiting mouse embryonic stem cell differentiation," Cellular Signalling, vol. 26, no. 10, pp. 2107-2116, 2014.

[23] M. C. Nostro, F. Sarangi, C. Yang et al., "Efficient generation of NKX6-1+ pancreatic progenitors from multiple human pluripotent stem cell lines," Stem Cell Reports, vol. 4, no. 4, pp. 591-604, 2015.

[24] F. W. Pagliuca, J. R. Millman, M. Gürtler et al., "Generation of functional human pancreatic $\beta$ cells in vitro," Cell, vol. 159, no. 2, pp. 428-439, 2014.

[25] A. Rezania, J. E. Bruin, P. Arora et al., "Reversal of diabetes with insulin-producing cells derived in vitro from human pluripotent stem cells," Nature Biotechnology, vol. 32, no. 11, pp. 1121-1133, 2014.

[26] M. Rostovskaya, N. Bredenkamp, and A. Smith, "Towards consistent generation of pancreatic lineage progenitors from human pluripotent stem cells," Philosophical Transactions of the Royal Society of London. Series B, Biological Sciences, vol. 370, no. 1680, p. 20140365, 2015.

[27] M. Ohori, T. Kinoshita, M. Okubo et al., "Identification of a selective ERK inhibitor and structural determination of the inhibitor-ERK2 complex," Biochemical and Biophysical Research Communications, vol. 336, no. 1, pp. 357-363, 2005.

[28] M. Öström, K. A. Loffler, S. Edfalk et al., "Retinoic acid promotes the generation of pancreatic endocrine progenitor cells and their further differentiation into beta-cells," PLoS One, vol. 3, no. 7, article e2841, 2008.

[29] J. Cai, C. Yu, Y. Liu et al., "Generation of homogeneous PDX1(+) pancreatic progenitors from human ES cell-derived endoderm cells," Journal of Molecular Cell Biology, vol. 2, no. 1, pp. 50-60, 2010.

[30] M. Johannesson, A. Ståhlberg, J. Ameri, F. W. Sand, K. Norrman, and H. Semb, "FGF4 and retinoic acid direct differentiation of hESCs into PDX1-expressing foregut endoderm in a time- and concentration-dependent manner," PLoS One, vol. 4, no. 3, article e4794, 2009.

[31] M. F. Abazari, F. Soleimanifar, M. Nouri Aleagha et al., "PCL/PVA nanofibrous scaffold improve insulin-producing cells generation from human induced pluripotent stem cells," Gene, vol. 671, no. 671, pp. 50-57, 2018.

[32] R. N. Mansour, F. Soleimanifar, M. F. Abazari et al., "Collagen coated electrospun polyethersulfon nanofibers improved insulin producing cells differentiation potential of human induced pluripotent stem cells," Artificial Cells, Nanomedicine, and Biotechnology, vol. 46, no. sup3, Supplement 3, pp. S734S739, 2018.

[33] S. E. Enderami, Y. Mortazavi, M. Soleimani, S. Nadri, A. Biglari, and R. N. Mansour, "Generation of insulinproducing cells from human-induced pluripotent stem cells using a stepwise differentiation protocol optimized with platelet-rich plasma," Journal of Cellular Physiology, vol. 232, no. 10, pp. 2878-2886, 2017. 